\title{
La reforma económica y la liberalización de la agricultura en México
}

DOI: $10.32870 /$ mycp.v8i26.265

José Jaime López Jiménez*

\section{Introducción}

$\mathrm{E}$ 1 presente trabajo analiza la liberalización de la agricultura de México durante el periodo 1982-2000, en el contexto de la reforma económica emprendida por el país durante la década de los años ochenta. A partir de 1982 México inició una serie de reformas tendientes a la reestructuración y apertura de su economía, que dio como resultado un modelo de desarrollo distinto al que había seguido el país hasta ese año. Como parte de este proceso, al igual que otros sectores productivos, la agricultura experimentó importantes cambios debido a que su estructura y funcionamiento estaban estrechamente vinculados al modelo de desarrollo anterior, - la sustitución de importaciones - en el cual era una actividad protegida de la competencia externa, gozaba de fuertes subsidios y transferencias públicas, y padecía de una amplia regulación e intervención estatal.

El trabajo está dividido en tres partes. La primera describe brevemente las reformas implementadas en el país y contrasta las medidas de política más relevantes con sus principales efectos en el contexto macroeconómico. La segunda analiza el proceso de reestructuración de la agricultura de México, y subraya los principales cambios que se llevaron a cabo dentro de la política

\footnotetext{
* Profesor-investigador del Departamento de Estudios del Pacífico de la Universidad de Guadalajara, y miembro del SNI.
}

agrícola a fin mejorar la productividad y de insertar a la agricultura mexicana en el mercado internacional. La tercera estudia las tendencias estructurales de la agricultura mediante el comportamiento de algunos indicadores. Finalmente, se presentan algunas reflexiones respecto a los cambios en la agricultura mexicana.

\section{La intervención del Estado en la economía y la reforma económica}

La política de fomento del crecimiento económico

Al concluir la Revolución en 1921, el prolongado proceso de consolidación del nuevo régimen paulatinamente dio lugar a la constitución de nuevas formas de organización de la vida política, social y económica de México. En lo económico, una vez consolidadas las instituciones creadas con dicho movimiento, el país mostró un desempeño relativamente estable durante las siguientes dos décadas, lo que transformó la economía en todos los ámbitos. Este crecimiento de la economía propició mejoras en el empleo y el ingreso, lo que aunado al aumento del gasto público en infraestructura agrícola —que permitió un rápido crecimiento de la producción agrícola - y en los servicios, condujo a una mejoría en el nivel de vida de la población, especialmente en las zonas urbanas.

En esta etapa de desarrollo, el crecimiento y la estabilidad se retroalimenta- 
ron de tal manera que, por una parte, el crecimiento permitía elevar los ingresos fiscales que el aumento del gasto público requería y, por otra parte, generar las divisas que el propio crecimiento demandaba, sin necesidad de recurrir a devaluaciones ni a deuda externa. Además, ello permitía mantener la inflación bajo control, y todo - en conjunto- creó un clima en el que las oportunidades de inversión se multiplicaron y que dejó poco campo a la especulación con los recursos potencialmente productivos. ${ }^{1}$

Pero el factor fundamental que posibilitó el crecimiento con estabilidad fue el modelo de industrialización por sustitución de importaciones adoptado a partir de la década de los cuarenta, cuyo elemento central era precisamente el proteccionismo. Sin embargo, con el tiempo éste habría de convertirse en el principal obstáculo para la expansión de la economía al producirse una serie de problemas estructurales, que a la postre condujo al agotamiento del modelo. De esta forma, la protección de la economía se convirtió en una especie de condición para el surgimiento de nuevas industrias y después para la existencia de las mismas, porque no se establecieron metas claras para su supervivencia en un determinado plazo, a cambio del subsidio implícito en dicha protección y otras medidas de fomento que la complementaron. ${ }^{2}$

Esto propició cierto conformismo en el sector empresarial que condicionó en cierta forma su relación con el gobierno y prefirió la vía de la negociación de privilegios más que buscar una estrategia de participación para la generación de ventajas de competitividad. De ahí que gran parte del esfuerzo de introducción de nuevas actividades en los años cincuenta estuviera directamente a cargo del gobierno, sobretodo en ramas como la siderúrgica, fabricación de papel y equipo para transporte, entre otras. Un segundo problema inherente a este modelo de desarrollo fue la articulación entre la agricultura y la industria, donde la primera se vio empujada a apoyar al proceso de industrialización mediante la provisión de bienes a bajo costo, mano de obra barata, abasto de materias primas y generación de divisas, gracias al crecimiento sostenido de la producción agrícola hasta mediados de los años sesenta (Solís, 2000: 156-164).

Cabe anotar que este proceso estuvo sustentado en la reforma agraria, las innovaciones institucionales del cardenismo y la inversión en obras de irrigación e infraestructura agropecuaria por parte del gobierno en la década posterior. No obstante, el establecimiento de una articulación recíproca entre la agricultura y la industria también suponía el cumplimiento de ciertas funciones de apoyo de la segunda hacia la primera, entre ellas el suministro eficiente de insumos baratos para impulsar el crecimiento de la producción agrícola y la suficiente absorción de mano de obra liberada en determinado momento por el agro, aspectos que se creía que mejorarían el ingreso de la población rural.

Estas funciones se cumplieron en cierta medida, pero no en la magnitud requerida para mantener el ritmo de expansión del sector agropecuario una vez que la inversión pública en el mismo fue disminuyendo. El modelo de desarrollo agropecuario resultante de esta desigual dotación de estímulos a la agricultura provocó, por una parte, el surgimiento de una agricultura marcadamente polarizada en cuanto al acceso a riego y crédito $\mathrm{y}$, por la otra, la aparición de un amplio sector informal urbano debido a la incapacidad de la industria y los servicios para absorber a la población desplazada del medio rural, en un periodo de elevado crecimiento demográfico (Prud'Homme, 1995: 13). 
A nivel macroeconómico, la sustitución de importaciones como eje del crecimiento prácticamente cesó a partir de los años setenta. Con ello desaparecieron las bases de la estabilidad y el déficit público pasó a cumplir la función de factor de crecimiento, lo que ocasionó rápidamente un fuerte deterioro en la balanza de pagos. Así, conforme el déficit externo aumentaba, sus tradicionales fuentes de financiamiento - la agricultura y los servicios - tendieron a debilitarse, y el gobierno tuvo que recurrir crecientemente al endeudamiento externo.

A menudo, el crecimiento fue interrumpido por políticas restrictivas que buscaron revertir los desequilibrios que lo caracterizaron. Pero estos desequilibrios, aunados al aumento de la inflación y la creciente incertidumbre que las mismas políticas provocaron, fomentaron la especulación y la fuga de capitales. En este contexto, a mediados de los años setenta los esfuerzos del Estado por recuperar el crecimiento condujeron a una mayor profundización de los desequilibrios macroeconómicos, y éstos a su vez se erigían en obstáculos cada vez más grandes para el crecimiento. Las exportaciones masivas de petróleo de finales de los años setenta fueron un factor fundamental que permitió mantener el modelo en funcionamiento, en tanto no se implementó el modelo de exportación. Posteriormente, cuando el crecimiento de las exportaciones petroleras se detuvo y el acceso a los mercados de capital se restringió, la situación económica se tornó insostenible y el país entró de lleno en una grave crisis financiera.

\section{El ajuste estructural y la apertura de la economía}

A principios de los ochenta el modelo de desarrollo económico que había seguido
México durante cuatro décadas, basado en la sustitución de importaciones, experimentó graves desequilibrios financieros que tornaron inevitable la adopción de un conjunto de medidas de ajuste para estabilizar la economía y cambiar su estructura. La estrategia de desarrollo aplicada desde la década de los años cuarenta se sustentó en la protección del mercado interno a través de barreras arancelarias y no arancelarias contra las importaciones que mantuvieron al aparato productivo virtualmente aislado de la competencia internacional. Bajo esta estrategia, el Estado desempeñó un papel central al asumir un alto grado de proteccionismo y regulación de la actividad económica.

La insuficiente captación de ingresos fiscales, especialmente los tributarios, para sostener el elevado gasto público en la promoción del desarrollo industrial del país obligó a las autoridades a recurrir cada vez más al endeudamiento externo —esta situación vulneró el Estado y la planta productiva nacional-. Fue así como la crisis de la deuda externa que se presentó en agosto de 1982, al término de la administración de José López Portillo, provocó el inicio de las reformas económicas. La incapacidad del país para cumplir con sus acreedores externos significó el agotamiento del modelo en que se había sustentado el crecimiento económico, asociado con el bajo nivel de los precios internos a causa de la intervención del Estado.

A partir de 1982, con el arribo de Miguel de La Madrid Hurtado, se inició un amplio proceso de reestructuración de la economía, mediante el cual el aparato productivo se orientó hacia un nuevo modelo de desarrollo caracterizado por un mayor equilibrio en las finanzas públicas, una menor intervención del Estado en las actividades productivas, la apertura comercial 
externa y la desregulación de la economía. ${ }^{3}$ El objetivo de este nuevo modelo consistió en insertar a la economía mexicana en las grandes redes internacionales de producción y comercialización en el marco de la globalización de la economía mundial, así como en liberalizar las fuerzas del mercado para lograr una asignación más eficiente de los recursos.

Ante las drásticas restricciones presupuestarias implementadas durante los años ochenta y bajo la nueva estrategia económica neoliberal, el Estado inició un programa de ajuste económico mediante la aplicación de diversas medidas, entre las que destacan la privatización - el cierre o la disminución de las empresas estatales-. Esta menor intervención pública se reflejó en la reducción del gasto en inversión y en los apoyos que el gobierno destinaba a las actividades productivas - como la agricultura-, lo que en la práctica implicó la liberación de precios y el recorte de los subsidios a los insumos y al crédito.

Con respecto a la apertura comercial, se puede establecer que a partir del ingreso de México al Acuerdo General sobre Aranceles y Comercio (GATT, por sus siglas en inglés) en 1985, hoy Organización Mundial del Comercio (OMC), las barreras arancelarias y no arancelarias se fueron reduciendo gradualmente con la finalidad de permitir la libre importación de bienes del exterior, lo que sometió a los productores nacionales a una intensa competencia que privilegiaba la competitividad en el mercado. El Tratado de Libre Comercio de América del Norte (TLCAN), que entró en vigor en 1994, así como los recientes tratados de libre comercio con los países de la Unión Europea, Centroamérica y Japón, no son otra cosa sino la consolidación de este proceso.
La desregulación de la economía tuvo como objetivo central crear un marco legal que en lugar de inhibir la inversión privada nacional y extranjera - como ocurrió en el pasado-, la promovía con la reducción de los requisitos legales exigidos. Las reformas a la Ley de Inversión Extranjera realizadas en 1993 y la redefinición de las áreas estratégicas reservadas exclusivamente al Estado han sido los principales medios para alentar la inversión privada a fin de que se convierta en el motor de la economía nacional. Otro elemento fundamental de la nueva estrategia económica neoliberal fue el mantenimiento del equilibrio en las finanzas públicas. Las condiciones de estabilidad macroeconómica - el control de la inflación, por ejemplo—, que favorecen un mejor desenvolvimiento de la actividad productiva, se encuentran determinadas por un equilibrio fiscal, esto es, por un equilibrio entre ingresos y gastos públicos. Con ello se puede decir que la nueva política económica se basó en políticas fiscales y monetarias restrictivas, utilizadas desde el inicio del proceso de cambio estructural de la economía para estabilizar el crecimiento de los precios.

La contracción del gasto público y los incrementos de los precios y tarifas públicos, aunado a una política tributaria que fortalece los ingresos del gobierno, han sido las alternativas para reducir el déficit fiscal, que se considera uno de los causantes de presiones inflacionarias. ${ }^{4}$ No obstante los altos costos sociales que han implicado estas políticas económicas restrictivas y sus consecuencias en el ingreso de la población, especialmente entre la población rural, el gobierno se ha empeñado en sostener que son la mejor alternativa para promover el crecimiento y la estabilidad económica. 
Los principales resultados de la reforma económica

Los efectos iniciales de las reformas económicas fueron una severa recesión producto de la fuerte contracción en el gasto público, la inversión y el consumo. El crecimiento económico del país se contrajo sensiblemente al grado de presentar tasas negativas de $0.6 \%$ y $4 \%$ en 1982 y 1983 , respectivamente. Posteriormente, la producción nacional se vio afectada también por el terremoto y la nueva caída de los precios del petróleo de mediados de los años ochenta. Bajo estas circunstancias, la economía mostró un grave deterioro durante todo el periodo 1983-1988, el cual corresponde a una de las etapas más difíciles por las que ha atravesado el país. Fue hasta principios de los años noventa cuando se recuperó el crecimiento, al alcanzarse tasas superiores a 3\% anual promedio durante toda la década, si bien cabe anotar que este ritmo se vio afectado por la crisis financiera de 1995 cuyos efectos se sentirían hasta el primer lustro del nuevo siglo (tabla 1).

Con respecto a la inflación, el rápido ajuste fiscal permitió el control de los precios en los primeros años de las reforma. Posteriormente, la tasa de inflación comenzó a aumentar hasta llegar a casi $160 \%$ en 1987, alcanzando con ello el nivel más alto en la historia reciente de México. No obstante, a partir de 1988, con la profundización de la reforma estructural de la economía implementada por el nuevo gobierno, la inflación mostró una tendencia descendente hasta alcanzar niveles de un dígito a finales de los años noventa. Por otro lado, el costo social del ajuste se reflejó en la fuerte contracción de los salarios reales y en los niveles del desempleo. Entre 1983 y 1988, el salario mínimo en México presentó un crecimiento real negativo cercano a $10 \%$ promedio anual, situación que se agravó aún más en la segunda mitad de la década de los años noventa cuando nuevamente se presentó un crecimiento real negativo de alrededor de $14 \%$ anual promedio, lo que da una idea de la pérdida del poder adquisitivo de los trabajadores desde el inicio de las reformas en México. El desempleo, por su parte, mostró una tendencia descendente hasta ubicarse en un nivel cercano a $3 \%$ promedio anual en el mismo periodo, aunque es importante

Tabla 1

México: la evolución de la economía (Valores promedios anuales en porcentajes)

\begin{tabular}{lcccccc}
\hline Periodo & $\begin{array}{c}\text { Crecimiento } \\
\text { del PIB real }\end{array}$ & $\begin{array}{c}\text { Gasto } \\
\text { público /PIB }\end{array}$ & $\begin{array}{c}\text { Déficit o superávit } \\
\text { fiscal/ PIB }\end{array}$ & $\begin{array}{c}\text { Crecimiento } \\
\text { Inflación } \\
\text { del salarioa }\end{array}$ & $\begin{array}{c}\text { Desempleo } \\
\text { abierto }\end{array}$ \\
\hline $1966-1970$ & 7.9 & 4.4 & -0.5 & 3.2 & 0.0 & nd \\
$1971-1976$ & 6.2 & 11.3 & -3.5 & 15.2 & 13.9 & nd \\
$1977-1982$ & 6.1 & 18.1 & -5.1 & 31.7 & 28.0 & 4.6 \\
$1983-1988$ & 0.3 & 26.6 & -9.9 & 91.6 & 82.1 & 4.1 \\
$1989-1994$ & 3.9 & 16.8 & -1.1 & 16.9 & 20.9 & 3.1 \\
$1995-2000$ & 3.5 & 15.4 & -1.1 & 22.0 & 7.6 & 2.8 \\
$2001-2004$ & 2.1 & 12.0 & -1.6 & 5.6 & 5.3 & 2.0 \\
\hline
\end{tabular}

a. Salario mínimo mensual.

Fuente: FMI (1998, 2003 y 2005). 
señalar que existen serias dudas sobre la forma en que se calcula este indicador en nuestro país.

En el sector externo hubo un comportamiento muy variable ante el efecto de diversos factores. La misma apertura de la economía, aunada a los altibajos en los precios del petróleo, la disminución en la actividad económica interna y los ajustes en los precios relativos ocasionados por las sucesivas devaluaciones del tipo de cambio, se conjugaron para dar como resultado un rápido crecimiento de las manufacturas. Con ello, salvo la brusca caída que experimentaron a mediados de los años ochenta, las exportaciones mostraron un crecimiento constante hasta finales de los años noventa, aunque sin alcanzar los niveles de crecimiento previos a las reformas económicas, y disminuyeron nuevamente durante el primer lustro del nuevo siglo. Las importaciones, por su parte, también mostraron una fuerte caída al inicio de las reformas y, aun cuando mostraron una ligera recuperación durante la primera mitad de los noventa, incluso por arriba de las exportaciones, posteriormente seguirían una tendencia descendente hasta los primeros años del nuevo siglo, lo que se tradujo en un significativo déficit en la balanza de pagos del país (tabla 2).

\section{La liberalización de la agricultura mexicana}

Con la crisis de la deuda en 1982, la política agrícola de México experimentó un cambio radical con respecto a su anterior esquema. Los principios de este cambio se fundamentaron en el objetivo de hacer compatible el modelo de desarrollo agrícola con la nueva política macroeconómica, implantada a partir del gobierno de Miguel de la Madrid, profundizada con Carlos Salinas de Gortari y consolidada con Ernesto Zedillo. La política se enfocó hacia la competitividad, las ventajas comparativas y la inserción de México en el proceso de internacionalización de la agricultura. Con ello la nueva estrategia enfatizó principalmente la expansión del sector de frutas y hortalizas, productos de gran demanda en Estados Unidos, pero se desatendió el sector de básicos compuesto por los granos, las oleaginosas, los cárnicos y sus derivados.

Los propósitos antiinflacionarios, aunados a las nuevas doctrinas económicas

Tabla 2

México: la evolución del sector externo

(Valores promedios)

\begin{tabular}{lcccc}
\hline Periodo & $\begin{array}{c}\text { Crecimiento de } \\
\text { exportaciones }\end{array}$ & $\begin{array}{c}\text { Crecimiento de } \\
\text { importaciones }\end{array}$ & $\begin{array}{c}\text { Cuenta corriente } \\
\text { (mdd) }\end{array}$ & $\begin{array}{c}\text { Tipo de cambio } \\
\text { (pesos por dólar) }\end{array}$ \\
\hline $1966-1970$ & 4.4 & 9.5 & -686 & 0.0125 \\
$1971-1976$ & 16.7 & 18.3 & $-2,249$ & 0.0130 \\
$1977-1982$ & 41.1 & 27.0 & $-7,164$ & 0.0287 \\
$1983-1988$ & 5.2 & 12.0 & 1,891 & 0.8013 \\
$1989-1994$ & 12.2 & 19.1 & $-17,611$ & 2.9796 \\
$1995-2000$ & 18.5 & 14.6 & $-10,017$ & 8.3482 \\
$2001-2004$ & 5.8 & 5.3 & $-11,793$ & 10.2683 \\
\hline
\end{tabular}

Fuente: FMI $(1998,2003$ y 2005). 
neoliberales, justificaron el cambio en virtud de que los precios internacionales de los productos básicos habían disminuido notoriamente en los años ochenta y, lo más importante, que Estados Unidos había alcanzado grandes excedentes en la producción de básicos. Paralelamente, se consideró que la población económicamente activa (PEA) agrícola era demasiado extensa (28\%), por su pobre aportación al PIB nacional (8\%). Por lo tanto, el ajuste poblacional en el sector agropecuario se convirtió en una de las metas gubernamentales, sin que se contemplaran medidas compensatorias en términos de absorción de la mano de obra agrícola ni esquemas de apoyo acordes a las distintas regiones y tipos de productores.

En este sentido, rápidamente se abandonaron los objetivos de seguridad alimentaria y autosuficiencia privilegiados en el modelo anterior, así como la protección de los productores de escaso potencial productivo, que desde el gobierno de Lázaro Cárdenas fueron la prioridad nacional. Pero también es necesario señalar que los cambios en la política agrícola fueron adoptados sin una adecuada secuencia y sin mecanismos complementarios eficientes, lo que redundó en graves perjuicios para la gran mayoría de los agricultores.

Todo eso implicó una mayor desprotección de los productores, la disminución drástica de los subsidios a la producción, la eliminación de los precios de garantía, el retiro del Estado de la comercialización de la producción y el abandono de su papel rector de las actividades del campo. Las consecuencias económicas y sociales de estos cambios han sido muy importantes porque durante décadas la estrategia gubernamental para el campo había sido la opuesta: economía semicerrada, protección de los productores mediante la fijación de precios de garantía y subsidios a la producción, y una amplia intervención y regulación estatal en todos los mercados de productos e insumos. A continuación se exponen los principales cambios en la política agrícola, así como sus resultados en términos productivos y sociales.

\section{La reestructuración del crédito rural}

El Banco Nacional de Crédito Rural (Banrural), creado en 1976, cubría hasta el momento de las reformas gran parte de las necesidades de financiamiento de los productores ejidales. En 1988 atendió a $63 \%$ de los ejidos y $41 \%$ de los ejidatarios. Su rango de operación se extendía entonces a más de 7.2 millones de hectáreas y aproximadamente 1.5 millones de productores del sector social. Su forma de operar consistía en la instrumentación de un "crédito dirigido", mediante el cual se proporcionaron insumos al productor, quien tenía así escaso margen de control sobre el proceso productivo y sobre la retención del excedente. Sin embargo, se reconocía que el crédito aportaba subsidios al productor por medio de tasas de interés más bajas que las vigentes en el mercado, puesto que la diferencia entre ambas osciló entre 23\% y 25\% durante 1986-1987 (Cruz, 1995).

Otra forma de beneficio era la condonación de deudas, por lo que la banca sólo recuperaba entre $50 \%$ ó $60 \%$ de los préstamos. Este sistema también aceptaba la simulación de siniestros, forjados por la Aseguradora Nacional Agrícola y Ganadera (ANAGSA) - hubo quienes la catalogaron como una fábrica de siniestros- en complicidad con los productores y el propio banco. Así, a finales de los años ochenta la banca rural era todo un foco de corrupción e irregularidades, que se tradujeron en grandes pérdidas que debió absorber el gobierno. 
Con la reestructuración de Banrural, iniciada en 1989, se buscó eliminar estas prácticas y darle transparencia y credibilidad a sus funciones. Para ello se seleccionó sólo a aquellos productores del sector social con potencial productivo - cerca de 400 mil- y se transfirieron los 1.1 millones restantes al Programa Nacional de Solidaridad (Pronasol), institución que a partir de entonces funcionó como fuente de financiamiento de los campesinos más pobres. Esto significó una drástica caída del crédito rural, el cual se redujo alrededor de $70 \%$ en términos reales entre 1985 y 1994, lo que provocó una brusca disminución en la superficie beneficiada, que pasó de 7.2 millones de hectáreas en 1988 a sólo 1.3 millones en 1995 (INEGI, 1998).

Tales cambios también incidieron en el abandono de las áreas de temporal, las cuales en 1993 sólo representaron 10\% de la superficie habilitada en 1988. Por el contrario, como el financiamiento ahora fluía más hacia las áreas de riego, cambió la proporción de los recursos dirigidos a éstas de 40\% en 1988 a 70\% en 1994 (Cruz, 1995). Junto con Banrural operó el Fideicomiso Instituido con Relación a la Agricultura (FIRA), que benefició a los agricultores privados, si bien recientemente asumió también la tarea de suministrar recursos a una pequeña porción de ejidatarios prósperos, cuya cobertura correspondía antes a Banrural. Como entre 1985 y 1994 FIRA aumentó sus recursos $105 \%$ en términos reales, se convirtió en la principal fuente crediticia para el sector rural. A finales de los años noventa, FIRA aportaba alrededor de $80 \%$ del crédito agropecuario total.

Pronasol, por su parte, mediante mecanismos informales (sin garantías, ni contratos o pagarés), cubrió 2.5 millones de hectáreas y 1.3 millones de productores con menos de 2 hectáreas en promedio en
1994. Los créditos del Pronasol equivalían en 1992 a $\$ 355$ pesos por hectárea y $\$ 930$ pesos por productor. Estos créditos, cuyo retorno era canalizado a obras comunitarias, no siempre se utilizaron en actividades productivas, dado que en muchos casos su función se trasladó al ámbito del consumo más que al de la producción. Cabe agregar que el seguro agrícola, proporcionado por la banca oficial, disminuyó también su cobertura de 6.9 millones de hectáreas aseguradas en 1987 a sólo 500 mil hectáreas en 1994 (Cruz, 1995).

\section{La desregulación de la producción} y la distribución de insumos

La privatización de las dos mayores empresas estatales en el sector agropecuario fue otra de las medidas significativas de la nueva estrategia: Fertilizantes Mexicanos (Fertimex) y Productora Nacional de Semillas (Pronase). Vale la pena subrayar que en 1986 los precios del nitrógeno y del fósforo en México eran equivalentes a la mitad de los precios de importación, situación que propició un considerable incremento en la superficie fertilizada entre 1950 y 1990 , al pasar de $5 \%$ a $80 \%$ del total de la superficie cultivada (Gordillo, De Janvry y Sadoulet, 1999).

Si bien el subsidio a los insumos impulsó de manera importante la tecnificación del campo mexicano, dicho procedimiento comenzó a cuestionarse con el cambio de política agrícola. Fertimex fue privatizada y Pronase reestructurada y se vendió una gran parte de sus plantas. Con estas medidas se eliminaron los subsidios, se elevaron los precios de los insumos y, con ello, los costos de producción. Ello induciría a la descapitalización de los agricultores, pues mientras que los precios de los productos finales se duplicaron entre 1990 y 1995, 
los precios de los fertilizantes aumentaron $230 \%$ y el de otras materias primas utilizadas en la agricultura creció más de 150\% (Banco de México y Sagarpa) Todo ello condujo a una severa regresión en el nivel tecnológico del campo mexicano, en virtud de que hubo un descenso significativo en el número de productores que aplicaron tecnología moderna. Entre 1990 y 1994 el uso de fertilizantes entre los ejidatarios se redujo $52 \%$, el consumo de semillas mejoradas cayó $24 \%$, el uso de insecticidas se redujo $17 \%$ y sólo $8 \%$ de los ejeditarios recibió la asistencia técnica (Gordillo, De Janvry y Sadoulet, 1999).

\section{La eliminación de los precios de garantía y el retiro de Conasupo}

A partir de 1989 se eliminaron los precios de garantía de doce cultivos básicos que operaron desde la década de los años cincuenta, excluyéndose sólo el maíz y el frijol, los cuales continuaron bajo este esquema hasta 1994. En la nueva normativa los precios de garantía se sustituyeron por precios de concertación fijados previamente a la cosecha entre productores e industriales y utilizaron como referencia los precios internacionales. Paralelamente, se suprimieron las licencias de importación y se sustituyeron por aranceles, eliminándose también el monopolio de las importaciones que ejercía Conasupo. Los aranceles fijados en la mayor parte de los productos agrícolas tendieron a disminuir, con excepción de los rubros más sensibles como el maíz, bajo la estrategia de alinearlos con los precios internacionales.

Con estas medidas se eliminaron los subsidios implícitos en los precios de algunos bienes como el sorgo y la soya, sustituyéndose por un nuevo esquema de pagos directos al productor. A la vez, Conasupo, que anteriormente adquiría las cosechas de granos básicos para su posterior comercialización, abandonó parcialmente esta función al concentrarse exclusivamente en el maíz y el frijol. Con la finalidad de facilitar el retiro de Conasupo por etapas, se creó dentro de la Secretaría de Agricultura, Ganadería y Desarrollo Rural (Sagar) la filial Apoyos y Servicios a la Comercialización Agropecuaria (Aserca) en 1991, cuya función era mejorar los canales de comercialización a través de un esquema de precios de concertación, pero sin intervenir en el proceso de compra-venta, ya que sólo ayudaba a establecer contactos entre productores y consumidores de granos y oleaginosas mediante la creación de mercados regionales.

El sistema de apoyos a la comercialización que operaba Aserca era un esquema de precios que compensaba la diferencia entre el precio internacional de los granos puestos en el lugar de consumo nacional y el precio del producto nacional puesto en el mismo lugar. La diferencia entre ambos precios era el monto que entregaba Aserca al comprador, para que a éste en cierta forma le fuera indiferente comprar producto nacional o importado. Pese a los esfuerzos de Aserca, la nueva situación afectó a los productores, ya que perdían simultáneamente la protección arancelaria, el subsidio por la vía de los precios y la seguridad en la comercialización que les brindaba Conasupo. Ello propició que las importaciones crecieran fuertemente e impusieran los precios internacionales en el mercado mexicano, e incluso los redujo aún más dado que las facilidades para importar provocaron una sobreoferta interna. Por lo general, las importaciones se hacían $\mathrm{y}$ se siguen haciendo en periodos previos a las cosechas nacionales, de modo que a menudo los industriales no respetan lo pac- 
tado en términos de precios o adquisición de cosechas.

A raíz de esta situación, los productores de granos comenzaron a sustituir sus cultivos por los únicos granos protegidos —maíz y frijol—, y generaron nuevas distorsiones en la oferta de básicos. Sin embargo, a partir de 1994 — con el TLCAN— se abrió el mercado del maíz y frijol, y si bien el acuerdo establece que ambos productos sean considerados como "sensibles" y tendrán un plazo de 15 años para su total liberalización, las importaciones masivas se presentaron rápidamente. Por ejemplo, para 1996 el TLCAN fijó una cuota anual de 2.5 millones de toneladas de maíz para el ingreso a nuestro país libre de aranceles, pero según algunas fuentes ingresaron a México por esta vía 6.4 millones de toneladas sin pagar el arancel correspondiente (Fritscher y Steffen, 1994).

\section{El Procampo}

El Programa de Apoyos Directos al Campo (Procampo) se creó para sustituir los subsidios implícitos en los precios de garantía de algunos productos por pagos directos al productor. Adicionalmente, se ha buscado compensar al productor por los desequilibrios que se suscitan al confrontarse éste con sus competidores externos, principalmente con los estadounidenses, quienes reciben fuertes subsidios de sus respectivos gobiernos. Con todo, ninguno de los dos objetivos se ha podido lograr con este programa, pues si bien beneficia básicamente al productor de subsistencia, no logra compensar al productor comercial, ya que anteriormente el subsidio se asignaba por tonelada producida y no por unidad de superficie como ahora se otorga, por lo que cuanto mayor productividad se obtenía, mayor remuneración había.
Esto significa que hoy en día con el Procampo los productores que tienen los mayores índices de productividad sólo perciben una fracción del subsidio que anteriormente gozaron. Es importante anotar que los productores de otros países reciben subsidios por productividad y no por unidad de superficie, lo cual los hace más competitivos respecto al productor mexicano. Ello es más grave en el caso de aquellos productos que recibieron subsidios vía precios, sobre todo el maíz y en menor medida la soya y el sorgo.

\section{El Tratado de Libre Comercio de América del Norte (TLCAN)}

Se puede afirmar que el TLCAN vino a consolidar las reformas en la agricultura, dándoles permanencia e impidiendo algún retroceso en su aplicación. Si bien muchos tópicos de las modificaciones no fueron abordados en las negociaciones, como el de los subsidios, hay un calendario estricto para las desgravaciones arancelarias, lo que implica un escenario futuro de casi total liberalización comercial. Ello es así porque el comercio exterior agropecuario se realiza básicamente con Estados Unidos. El acuerdo con Canadá es más restringido, ya que, por un lado, las transacciones comerciales que México realiza con ese país son mínimas y, por otro lado, es un acuerdo menos ambicioso que el que se llevó a cabo con Estados Unidos en materia de desgravaciones.

Según el nuevo acuerdo, la apertura agropecuaria de los sectores involucrados en las negociaciones se realizará en forma gradual, en un periodo de 15 años, con plazos ajustados a la competitividad de los productos. Con ello, algunos sectores se desgravaron con la puesta en marcha del TLCAN, como son ganado bovino, carnes y derivados, 
algunas frutas y hortalizas, el sorgo, entre otros (categoría A). Otros productos de los sectores anteriores se desgravaron en los siguientes cinco años (categoría B). Mientras que en la categoría $\mathrm{C}$, a desgravarse a los diez años a partir de 1994, se incluyen la mayor parte de los granos (soya, trigo y arroz) así como otros productos frutícolas y hortícolas. Finalmente, se estableció una categoría $\mathrm{C}+$, a un plazo de 15 años, que se reserva para los productos más sensibles de cada país, lo que para México se traduce en una protección decreciente del maíz, el frijol y la leche.

\section{La reforma del Artículo 27}

Sin duda, la reforma social más importante de la década pasada fue la modificación de las leyes agrarias del país mediante la reforma del Artículo 27 constitucional, con el propósito de permitir, bajo ciertas circunstancias, la compra-venta, el arrendamiento y otras concesiones de la tierra, algo que estaba prohibido en la legislación anterior. Esta reforma legal fue complementada con un ambicioso programa de titulación de tierras conocido como Programa de Certificación de Derechos Ejidales (Procede), mediante el cual se ha regularizado la tenencia de la tierra y se han otorgado títulos de propiedad a más de la mitad de los ejidatarios.

La finalidad de estas reformas agrarias es propiciar el funcionamiento de un mercado de tierras que facilite la transferencia de la propiedad de los productores menos aptos a los más eficientes o con más potencial productivo, para aumentar la producción y productividad en el nuevo marco de apertura comercial y de inserción en los mercados internacionales. Otro de sus propósitos fue el combate contra el minifundio y el impulso a la asociación de los pequeños productores con agentes privados que cuenten con más capital y mejor tecnología y conocimiento de los mercados.

\section{El cambio en los incentivos a la producción}

Una vez expuestas las reformas económicas y sectoriales emprendidas por el Estado, se analizan sus efectos sobre el marco global de incentivos económicos en el que se desenvuelven los distintos tipos de productores. Es necesario no perder de vista que las nuevas políticas modernizadoras ven a los productores y al capital privado como los sujetos del desarrollo y que éstos actúan en una economía crecientemente dominada por el mercado. Cabría preguntarse, entonces, en qué medida la política agrícola neoliberal ha favorecido a la producción y la rentabilidad de las actividades agrícolas, y cómo han respondido los productores a este proceso de reestructuración.

Una forma de examinar los efectos de la reestructuración económica sobre la rentabilidad agrícola es a través de los precios agrícolas en términos reales, que mide los ingresos provenientes de la producción agrícola previamente deflactados. En el caso de México los precios reales agrícolas aumentaron en el periodo 1980-1987, pero a partir de 1988, fecha en que comienza el periodo de rápida apertura comercial, presentan un permanente descenso hasta hoy en día. Esto significa que los precios recibidos por los agricultores crecieron en forma más lenta que los precios al consumidor, lo cual debió ser un importante desestímulo a la producción agrícola. Otro indicador de la rentabilidad agrícola es la relación entre la evolución de los precios y los costos de producción. En la práctica 
esta relación se volvió desfavorable para los productores a partir de 1991, lo que también representa un desestímulo a la producción del campo.

Existen dos indicadores adicionales que muestran el deterioro del marco de incentivos para la producción agrícola. El primero es la caída de los precios reales agrícolas con respecto a los precios reales internacionales - o precios de frontera- a partir de 1994. Antes de ese año los precios reales internos eran superiores a los precios de frontera para granos básicos y oleaginosas, e inferiores a los precios de los bienes de exportación, principalmente frutas y hortalizas. Sin embargo, después de la devaluación del peso, los precios reales internos disminuyeron con respecto a los precios de frontera, lo que hizo más difícil la competencia en el mercado nacional para los productores de cereales.

El segundo indicador es el coeficiente de protección nominal, el cual mide la diferencia entre los precios internos nominales y los precios internacionales, ajustados para reflejar los costos de importación a los puntos de entrega en México, es decir, los costos relacionados con el transporte, almacenamiento, impuestos y financiamiento. Tales coeficientes fueron significativamente negativos entre 1992 y 1997 para todos los cereales y oleaginosas, con excepción del maíz, lo que revelaba la existencia de un impuesto implícito en estos cultivos. Dicha tendencia implica que las decisiones de la política económica condujeron a una disminución de los precios internos. Por lo tanto, la apreciación del peso y la liberalización comercial redujeron la protección de los productores nacionales durante los primeros años de los noventa. Por ejemplo, en 1994 se eliminaron las restricciones cuantitativas a las importaciones de maíz, trigo y frijol, y se sustituyeron por una cuota de importaciones libre de impuestos; además, se redujeron las tarifas para el sorgo, la soya y el arroz. Ambas medidas, la apreciación y la desprotección, hicieron posible la entrada de importaciones baratas que presionaron a la baja los precios nacionales (OCDE, 1997).

Este hecho requiere de algunas explicaciones, al mismo tiempo que se puede establecer un par de hipótesis. En lo que se refiere a los cultivos comerciales, los productores reciben apoyos directos y otro tipo de subsidios, de tal forma que les ha permitido contrarrestar la caída en la rentabilidad provocada por el deterioro en el marco de incentivos del mercado. Por su parte, los cultivos básicos como el maíz y el frijol han mostrado una baja sensibilidad a la caída en los precios internos debido a que son producidos para el autoconsumo, la engorda de animales y la venta en pequeñas cantidades para complementar el ingreso familiar, en el seno de unidades productivas cuya lógica no es la obtención de ganancias sino fundamentalmente la satisfacción de sus necesidades básicas.

La primera hipótesis puede ser explicada por el hecho de que en México, al mismo tiempo que se redujeron los subsidios a la producción a través de los precios y los insumos, se crearon nuevos mecanismos de apoyo como Procampo y el mecanismo de compensación de precios o apoyo al precio de mercado a través de Aserca, principalmente. Un indicador que mide el nivel de subsidios otorgados por el Estado a la agricultura es el Estimado del Subsidio al Productor (ESP). ${ }^{5}$

De acuerdo con datos de la OCDE, después de los fuertes recortes en el gasto y los apoyos destinados al sector, el ESP en México cayó hasta $3 \%$ en el periodo de 1983-1988, que corresponde al ajuste económico y al inicio de la apertura comercial, 
y aumentó posteriormente de manera notable hasta alcanzar 30\% entre 1989 y 1994 como resultado de los apoyos otorgados a través de Procampo. No obstante, a partir de la puesta en marcha del TLCAN y del Acuerdo sobre la Agricultura de la Ronda Uruguay del GATT, los subsidios a la agricultura mexicana tendieron a disminuir progresivamente durante los años noventa, empero nuevamente tendieron a aumentar de manera sustancial en los últimos años para compensar en cierta forma los efectos negativos ocasionados por el deterioro de los precios relativos internos (Gráfica 1).

\section{Las tendencias estructurales de la agricultura mexicana}

\section{El crecimiento del sector}

El producto nacional agropecuario experimentó un notable descenso durante las últimas dos décadas. Después de alcanzar tasas de crecimiento superiores a $6 \%$ en 1980 y 1981, el PIB agropecuario total cayó drásticamente a una tasa media anual de $0.8 \%$ en el periodo 1982-1992, y luego subió 1.9\% anual entre 1993 y 2004. De hecho, hasta la segunda mitad de los años noventa y principios del nuevo siglo se apreció una lenta recuperación del sector, aunque si bien estuvo lejos de alcanzar los niveles de crecimiento de principios de los años ochenta (tabla 3). Este aumento en la producción se debió a mayores rendimientos, particularmente del maíz, tanto en las áreas de riego como en las de temporal. Asimismo, durante los años noventa el área cosechada total creció a una tasa anual de $1 \%$, mayor que la observada en los años ochenta.

A su vez, se observó que el sector agropecuario perdió su importancia relativa dentro de la economía nacional. Mientras que entre 1980 y 1981 el PIB agropecuario representaba $8 \%$ del total nacional, en

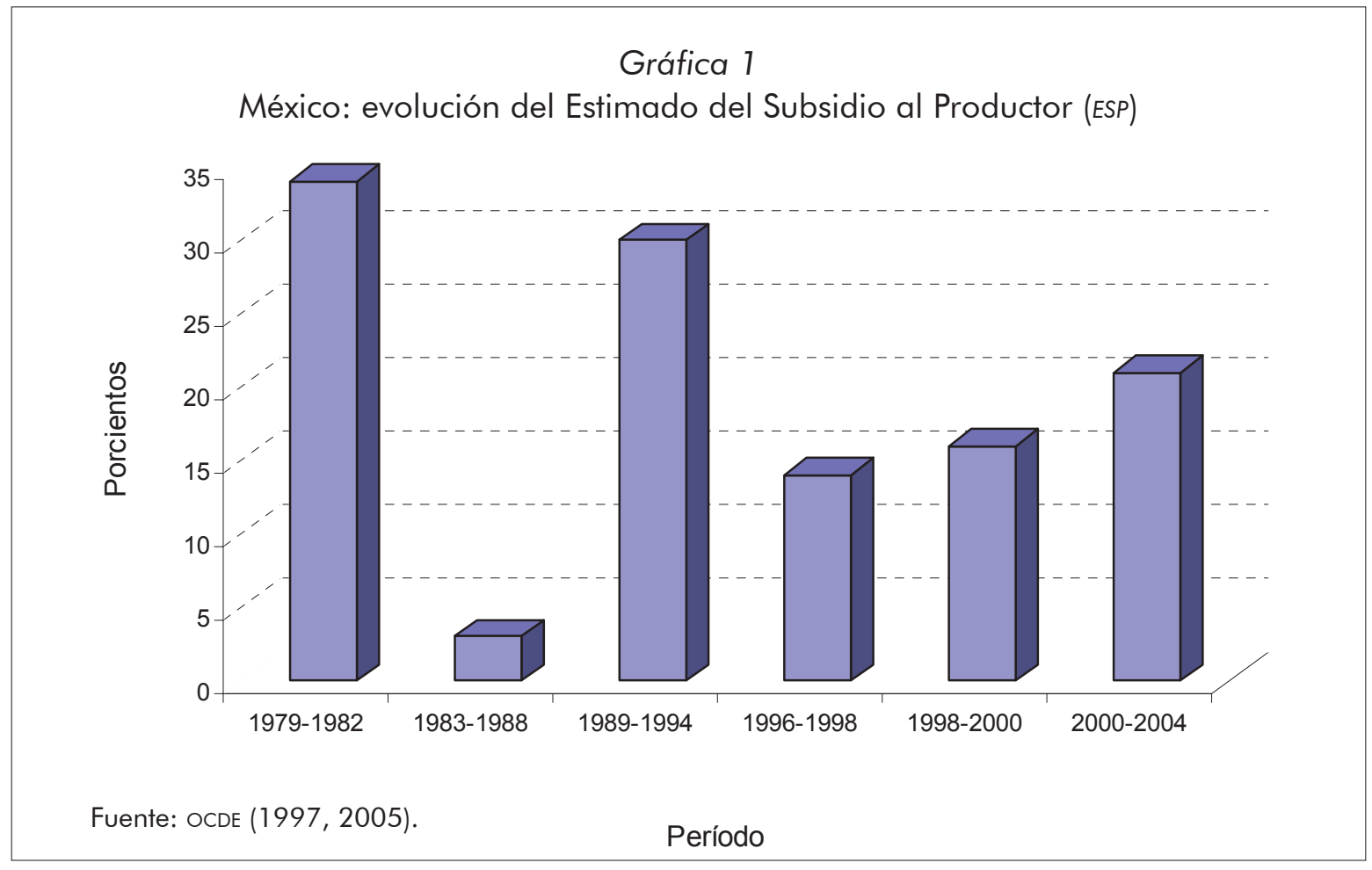


2004 su participación disminuyó a $6 \%$ (CEPAL, 2005: 7). Este descenso en la aportación de la agricultura al producto total nacional se debió, entre otros factores, a la misma reestructuración del sector -en lo particular- y a las reformas económicas - en general- iniciadas desde inicios de los años ochenta. Pero también habría que subrayar que los patrones de comportamiento de la producción agropecuaria no son homogéneos en el país, sino que difieren según los distintos subsectores y regiones de producción, es decir, según la actividad productiva y las características agro-ecológicas y socioeconómicas de cada región en particular.

Tabla 3

México: el crecimiento del PIB agropecuario, 1980-2004 (En porcentajes)

\begin{tabular}{lccc}
\hline Año & $\begin{array}{c}\text { PIB } \\
\text { agropecuario }\end{array}$ & Año & $\begin{array}{c}\text { PIB } \\
\text { agropecuario }\end{array}$ \\
\hline 1980 & 7.2 & 1992 & -1.0 \\
1981 & 6.1 & 1993 & 3.1 \\
1982 & -1.9 & 1994 & 0.2 \\
1983 & 2.2 & 1995 & 1.8 \\
1984 & 1.5 & 1996 & 3.8 \\
1985 & 3.0 & 1997 & 0.2 \\
1986 & -1.4 & 1998 & 3.0 \\
1987 & 1.1 & 1999 & 2.4 \\
1988 & -2.9 & 2000 & 1.5 \\
1989 & -0.1 & 2004 & 4.0 \\
1990 & 5.6 & $1982-1992$ & 0.8 \\
1991 & 2.3 & $1993-2004$ & 1.9 \\
\hline
\end{tabular}

Fuente: INEGI y CEPAL (2005).

Los cultivos de mayor dinamismo

Los cultivos de mayor dinamismo durante la última década fueron los forrajes, debido a la recuperación que experimentó la ganadería mexicana, especialmente cultivos como sorgo y avena cuyas producciones aumentaron $12 \%$ por año en el periodo 1993 -
2004 (CEPAL, 2005: 13). De igual forma, las hortalizas - principalmente, tomate, chile verde, brócoli, espárrago y pepino—-se han visto favorecidas por un creciente acceso al mercado de Estados Unidos, así como por las innovaciones tecnológicas introducidas. Cabe señalar que la participación de las exportaciones de tomate mexicano en el mercado estadounidense se elevó de $23 \%$ a $70 \%$ entre 1990 y 2003 , en gran parte como resultado del TLCAN (Rosenzweig, 2005: 32).

En el caso del jitomate -la principal hortaliza de exportación - se introdujo una variedad de semilla de larga vida en anaquel — desarrollada en Israel—, que ha incrementado de manera importante la competitividad de los productores mexicanos en el mercado norteamericano, gracias a que esta variedad no se ha podido adaptar en las zonas productoras de tomate de Estados Unidos. Sinaloa se ha convertido en el principal productor de jitomate de exportación, debido a que alrededor de $40 \%$ de la superficie cultivada utiliza dicha tecnología (tabla 4).

Otro grupo de cultivos dinámicos son los frutales - no tienen la misma intensidad que las hortalizas-, que también han registrado importantes crecimientos de productividad. Así mismo, la exportación ha sido el principal motor de crecimiento, ante la saturación del mercado nacional. Entre los cultivos de mayor crecimiento están: papaya, piña, sandía, jícama, fresa, guayaba, aguacate, mango y naranja. En los casos de la naranja y el plátano, las principales regiones productoras son la sur y la este - sobresale el estado de Chiapas-, que han importado tecnología de Centroamérica, mientras que el aguacate y el limón provienen principalmente de la región centro-oeste, especialmente de los estados de Michoacán y Colima. 
La reforma económica y la liberalización de la agricultura en México

Tabla 4

México: la producción de los principales cultivos, 1994-2004

(Miles de toneladas)

\begin{tabular}{|c|c|c|c|c|c|}
\hline \multirow[t]{2}{*}{ Cultivo } & \multirow[t]{2}{*}{1994} & \multirow[t]{2}{*}{2000} & \multirow[t]{2}{*}{2004} & \multicolumn{2}{|c|}{ Crecimiento medio anual (\%) } \\
\hline & & & & 1988-1993 & 1993-2004 \\
\hline \multicolumn{6}{|l|}{ Granos } \\
\hline Arroz & 374 & 351 & 279 & -8.9 & -0.3 \\
\hline Cebada & 307 & 713 & 932 & 7.8 & 5.1 \\
\hline Frijol & 1364 & 888 & 1,163 & 8.3 & -0.9 \\
\hline Maíz & 18,236 & 17,557 & 21,686 & 11.3 & 1.6 \\
\hline Sorgo & 3,701 & 5,842 & 7,004 & -15.2 & 9.5 \\
\hline Trigo & 4,151 & 3,493 & 2,321 & -0.5 & -3.9 \\
\hline \multicolumn{6}{|l|}{ Forrajes } \\
\hline Alfalfa verde & 21,122 & 23,150 & 26,196 & 3.2 & 3.1 \\
\hline Avena & 1,706 & 3,947 & 8,934 & 2.7 & 12.8 \\
\hline Maíz & 4,336 & 5,375 & 9,417 & 6.7 & 6.8 \\
\hline Sorgo & 2,051 & 3,811 & 5,057 & 1.9 & 12.0 \\
\hline \multicolumn{6}{|l|}{ Oleaginosas } \\
\hline Cártamo & 64 & 96 & 231 & -23.7 & 12.4 \\
\hline Copra & 215 & 202 & 225 & -2.0 & 0.4 \\
\hline Semilla de algodón & 187 & 123 & 212 & -37.6 & 15.9 \\
\hline Soya & 523 & 102 & 133 & 17.1 & -11.3 \\
\hline \multicolumn{6}{|l|}{ Hortalizas } \\
\hline Brócoli & 131 & 244 & 289 & 11.4 & 5.2 \\
\hline Chile verde & 766 & 1,742 & 1,867 & 8.0 & 7.1 \\
\hline Espárrago & 36 & 50 & 59 & -2.7 & 8.8 \\
\hline Jitomate & 1,376 & 2,086 & 2,315 & -1.7 & 2.9 \\
\hline Pepino & 262 & 459 & 518 & 0.5 & 5.6 \\
\hline Tomate verde & 337 & 580 & 723 & 11.6 & 6.3 \\
\hline \multicolumn{6}{|l|}{ Hortofrutícolas } \\
\hline Fresa & 95 & 141 & 177 & 4.1 & 5.9 \\
\hline Jícama & 96 & 122 & 169 & 3.6 & 6.2 \\
\hline Melón & 447 & 603 & 534 & -2.0 & 2.8 \\
\hline Sandía & 428 & 1,049 & 1,003 & -3.4 & 9.0 \\
\hline \multicolumn{6}{|l|}{ Frutas } \\
\hline Aguacate & 800 & 907 & 987 & 0.8 & 3.1 \\
\hline Durazno & 154 & 147 & 202 & -2.1 & 2.6 \\
\hline Guayaba & 186 & 254 & 303 & 3.6 & 4.2 \\
\hline Mango & 1,118 & 1,559 & 1,573 & 1.1 & 2.9 \\
\hline Naranja & 3,191 & 3,813 & 3,977 & 7 & 2.9 \\
\hline Papaya & 489 & 672 & 788 & -8.9 & 10.1 \\
\hline Piña & 229 & 522 & 669 & -11.3 & 11.0 \\
\hline Plátano & 2,295 & 1,871 & 2,361 & 1.2 & 0.6 \\
\hline Uva & 537 & 372 & 305 & -3.3 & -3.8 \\
\hline \multicolumn{6}{|l|}{ Industriales } \\
\hline Cacao & 43 & 28 & 44 & -1.8 & -1.8 \\
\hline Caña de azúcar & 40,587 & 42,373 & 48,662 & 0.1 & 1.1 \\
\hline
\end{tabular}

Fuente: CEPAL (2005). 


\section{Los cultivos de crecimiento moderado}

Aunque la producción de granos básicos creció cerca de $2 \%$ anualmente en promedio durante el periodo 1993-2004, el comportamiento de este subsector ha sido muy desigual. Mientras que la producción de sorgo y cebada mantuvo un crecimiento importante durante la última década, la de arroz, frijol, maíz y trigo disminuyó notablemente. De igual forma, si bien los rendimientos del cultivo de maíz y sorgo presentaron un crecimiento considerable, los de arroz y trigo se mantuvieron prácticamente sin movimiento, $\mathrm{y}$, por el contrario, los rendimientos en frijol disminuyeron significativamente. ${ }^{6}$

Dentro de los cereales, los cambios más importantes se registraron en el cultivo del maíz. En 1989, al eliminarse los precios de garantía para todos los cultivos excepto para el maíz y frijol, un gran número de productores, sobre todo de la región Noroeste, dejó de sembrar trigo y soya, principalmente, y comenzaron a sembrar maíz. Esto trajo como consecuencia que en 15 años, de 1989 a 2004, la producción de maíz creciera de 11 a 21.7 millones de toneladas, es decir, casi se duplicó en menos de dos décadas. De ahí que, ante la drástica caída en la rentabilidad de la mayoría de los cultivos, muchos agricultores -incluidos algunos productores de cultivos comerciales- comenzaron a considerar al maíz como un cultivo más atractivo y seguro. Esta situación vendría a reforzarse con la instrumentación del Procampo en 1994.

Si bien la mayor superficie sembrada de maíz explica este comportamiento de la producción del grano, el aumento en la productividad también contribuyó a dicho crecimiento. Los mayores rendimientos obedecen a que parte de las tierras que se destinaba a otros cultivos, en la que ahora se cultiva maíz, eran de riego, pero también se han observado mejoras tecnológicas en la producción de maíz, gracias a que las empresas transnacionales productoras de semillas han introducido variedades de alto rendimiento para tierras de riego y temporal. Por ejemplo, en regiones con agricultura de temporal como la centro-oeste, particularmente en La Barca, Jalisco, con la introducción de paquetes tecnológicos integrales - que incluyen épocas de siembra, manejo de suelos, dosis de fertilizantes, uso de plaguicidas y semillas mejoradas - se han alcanzado rendimientos de maíz de hasta 15 toneladas por hectárea, cuando la media nacional es de sólo 2.3 toneladas por hectárea. En el caso de la región noroeste, principalmente el estado de Sinaloa, donde se ha registrado el principal incremento, tanto en la superficie sembrada como en la producción de maíz a escala nacional, ha recibido fuertes apoyos para la comercialización de este grano (Casco y Rosenzweig, 2000).

\section{El empleo agropecuario}

En términos generales, el bienestar de la población en el campo mexicano acentuó su deterioro con las reformas económicas de inicios de los años ochenta, lo que se tradujo en mayor desempleo, pobreza y desigualdad en el medio rural. De acuerdo con los últimos censos agropecuarios de 1981 y 1991, la mano de obra empleada en las actividades agropecuarias aumentó de 8.1 a 10.9 millones de personas, esto es, $35 \%$ más en una década. Según los censos este aumento provino básicamente de la mano de obra no remunerada, la cual se incrementó en poco más de 3.5 millones de personas, ya que la mano de obra remunerada disminuyó $23 \%$, o sea, alrededor de 700 mil empleos. 
Sin embargo, de acuerdo con la Encuesta Nacional de Empleo de 1998, la población empleada en el sector agropecuario disminuyó a 7.8 millones de personas en ese año, lo que significa un descenso de $28 \%$ entre 1991 y 1998 . Esta tendencia continuó hasta 2004 , al ubicarse la población ocupada en 6.9 millones de personas, es decir, 37\% menos que en 1991. El paulatino descenso observado en el empleo agropecuario constituye un reflejo de los efectos del TLCAN sobre la agricultura mexicana (Rosenzweig, 2005).

Como se puede apreciar, de acuerdo con las diversas fuentes y supuestos, es posible afirmar que en los últimos años el desempeño del sector agropecuario se ha visto acompañado de una constante reducción de la mano de obra ocupada. Parece ser que las políticas agrícolas y el entorno económico nacional e internacional se han tornado menos favorables para la gran mayoría de los productores agrícolas, al provocar una disminución de la fuerza de trabajo en las actividades del campo y, con ello, un aumento en las migraciones hacia las zonas urbanas del país o hacia los Estados Unidos en busca de empleo.

\section{El ingreso rural}

En términos generales, la evolución de los salarios en el sector agropecuario ha sido similar a la evolución de los salarios reales promedio del conjunto de la economía. Con la crisis económica de 1995 los salarios reales en el sector agropecuario disminuyeron sensiblemente, si bien posteriormente hubo una recuperación de los salarios en general, mas no en la agricultura. Cabe señalar que entre 1994 y 1997 los salarios promedio agrícolas se derrumbaron alrededor de $30 \%$, aunque luego se recuperaron parcialmente en los años siguientes. Durante el periodo 1994-2004 el salario medio agropecuario presentó una tasa negativa de crecimiento de 1\% anual, y representó 59\% del salario medio nacional en dicho periodo (tabla 5).

Tabla 5

El salario real promedio en el sector agropecuario, 1994-2004a

(En pesos de julio de 2002)

\begin{tabular}{lrrrc}
\hline Año & Nacional & Sector agropecuario & $\begin{array}{r}\text { Tasa de crecimiento } \\
(\%)\end{array}$ & $\begin{array}{c}\text { Agropecuario/nacional } \\
(\%)\end{array}$ \\
\hline 1994 & 179.0 & 107.4 & -- & 60.0 \\
1995 & 151.1 & 88.7 & -17.4 & 58.7 \\
1996 & 134.6 & 77.9 & -12.1 & 57.9 \\
1997 & 132.3 & 77.7 & -0.3 & 58.7 \\
1998 & 134.7 & 79.5 & 2.3 & 59.0 \\
1999 & 135.3 & 80.5 & 1.3 & 59.5 \\
2000 & 141.8 & 84.6 & 5.2 & 59.7 \\
2001 & 150.4 & 89.9 & 6.2 & 59.8 \\
2002 & 154.6 & 92.6 & 3.0 & 59.9 \\
2003 & 156.9 & 94.0 & 1.5 & 59.9 \\
2004 & 162.8 & 96.9 & 3.1 & 59.5 \\
Promedio 1994-2004 & 149.4 & 88.4 & -1.0 & 59.2 \\
\hline
\end{tabular}

a. Incluye agricultura, ganadería, silvicultura y pesca.

Fuente: Rosenzweig (2005). 
En este sentido, se podría afirmar que el aumento registrado en la productividad del sector durante la década pasada no se ha traducido en un aumento del ingreso rural. Por otra parte, contrario a lo que se esperaba con la puesta en marcha del TLCAN, los salarios en general no han experimentado una convergencia con los salarios de Estados Unidos.

En lo que se refiere a la pobreza, de acuerdo con un estudio del INEGI y la CEPAL, la población que vive bajo condiciones de pobreza en el medio rural pasó de 14 millones en 1984 a 19 millones en 1992. De esta forma, mientras que en 1984 alrededor de $47 \%$ de los pobres se ubicaba en las zonas rurales, para 1992 esta cifra había aumentado a $51 \%$. Por su parte, la población que vive en pobreza extrema en las zonas rurales se incrementó de 6.7 a 8.8 millones de personas entre 1984 y 1992 (INEGI y CEPAL, 1994). Posteriormente, la crisis económica de 1995 profundizó la pobreza en el medio rural, al grado de que más de la mitad de la población rural no pudo cubrir sus necesidades alimenticias, por lo que a finales de los años noventa 8 de cada 10 personas eran pobres. No obstante, en 2004 las cifras se redujeron a $28 \%$ y a seis personas, respectivamente (Rosenzweig, 2005).

Con respecto a la distribución del ingreso, la encuesta de ingreso y gasto de 1996 realizada por el INEGI y la CEPAL, registró un Coeficiente de Gini para las zonas rurales de 0.398 y para las zonas urbanas de $0.434,{ }^{7}$ lo cual sugiere que la distribución del ingreso era relativamente más equitati- va en las zonas rurales que en las urbanas. Sin embargo, otros autores usaron una muestra del Censo de Población y Vivienda de 1990, y obtuvieron Coeficientes de Gini más altos, de 0.75 para las zonas rurales y de 0.64 para las urbanas, lo que expresa una relación diferente entre las áreas rurales y urbanas a la reportada por la encuesta de ingreso y gasto, por lo que la distribución del ingreso en las zonas rurales sería menos equitativa que en las rurales (Cácerez y Rubalcava, 1994). De lo que no hay duda es que, en términos generales, el impacto de las políticas macroeconómicas y agropecuarias sobre el ingreso de los productores agropecuarios ha sido desfavorable, aunque es importante reconocer que tal impacto ha sido distinto según el tipo de productor y de bien producido.

\section{Conclusión}

En los últimos 20 años dos procesos han caracterizado al sector agropecuario mexicano. Por un lado, existe un cambio constante en su entorno que incluye la estructura de los mercados agrícolas internacionales, las nuevas orientaciones macroeconómicas internas, su grado de inserción en la economía global, la disponibilidad de tecnología, así como una nueva concepción y ejecución de la política agropecuaria. Por otro lado, están los procesos económicos y sociales que tienen lugar a escala local y regional para adaptarse a esta nueva realidad.

El retiro del Estado del campo, la reestructuración y la desaparición de empresas 
estatales dejaron grandes vacíos institucionales y debilitaron ciertos mercados: financiamiento rural, aseguramiento agrícola y asistencia técnica. Estos vacíos institucionales y el deficiente funcionamiento de los mercados han limitado la capacidad de los pequeños productores para competir en los mismos y mejorar sus ingresos. De igual forma, se observa un estancamiento tecnológico en la agricultura campesina, expresado en un menor uso de fertilizantes, semillas mejoradas y agroquímicos, tendencia que está vinculada con mercados inestables, aumentos de costos de producción, disminución de la rentabilidad y financiamiento rural escaso y caro, sobre todo para los pequeños productores.

En este contexto la reestructuración de la economía - y de la agricultura en particular - implementada en México desde principios de los años ochenta, se ha traducido en incentivos desfavorables para los pequeños productores agrícolas. A pesar del adverso clima de incentivos, el sector agropecuario mexicano experimentó un modesto crecimiento y una diversificación productiva. Este aumento en la producción se debió a la implementación de algunos programas de apoyo, como Procampo y Alianza para el Campo. Mientras que el primero favoreció la producción para el autoconsumo y la seguridad alimentaria de las familias rurales de más bajos ingresos, el segundo propició cierta diversificación de la estructura de producción y del ingreso de los agricultores mexicanos.

De igual forma, este contexto desfavorable produjo resultados negativos en términos del ingreso rural y del bienestar de la población rural, que se hubieran agravado en caso de no mediar las remesas provenientes de una creciente migración y de la movilidad de trabajadores familiares a empleos agropecuarios de bajos ingresos, así como a otros empleos rurales no agropecuarios y actividades informales en los centros urbanos.

Esto significa que la respuesta de buena parte de los agricultores mexicanos se ha traducido en el reforzamiento de sus formas tradicionales de reproducción social. El estancamiento tecnológico de una buena parte de ellos ha implicado el retorno a formas de producción tradicional y a recurrir a actividades no agrícolas para complementar su ingreso. Por lo que, en el caso de México, la reestructuración de la agricultura ha puesto en evidencia la persistencia y flexibilidad de gran parte de las unidades de producción rural, por un lado, pero también la capacidad de transformación de un pequeño sector de productores empresariales para adaptarse a los cambios en los mercados agropecuarios nacionales e internacionales. กํํㄹ

\section{Notas}

1 A este respecto se recomienda el trabajo de Prud'Homme (1995: 12).

2 Existen numerosos trabajos que profundizan en el análisis de este periodo, entre ellos están los de Hansen (1993), De la Peña (1991), y Solís (2000).

3 Con relación al proceso de reestructuración de la economía, véanse los trabajos de Lustig (1994), Solís (2000), UAM-A (1995) y Rueda (1998).

4 Otra medida importante fue la eliminación del control sobre los precios de un conjunto de bienes y servicios, entre los que destacan los productos alimenticios básicos. La última acción fue la supresión del precio oficial de la tortilla, cuyo precio de mercado entró en vigor a principios de 1999.

$5 \quad$ El ESP es un coeficiente que mide los apoyos totales del Estado otorgados a los productores, como porcentaje del valor total de la producción agropecuaria o por tipo de producto. Incluye los pagos en efectivo, los apoyos al precio de mercado, los subsidios a los insumos y al crédito, y las transferencias indirectas por concepto de investigación, asistencia técnica, capacitación y sanidad, entre otros.

MÉXICO YLACUENCADEL PACÍFICO vol. 8, núm. 26 / septiembre-diciembre de 2005

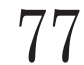


6 La caída en los rendimientos del sorgo se debe a la incidencia de malos temporales en la región noreste - la principal zona de producción-, y a que los productores redujeron el uso de fertilizantes en respuesta a la caída de los precios de este cultivo.

7 Este coeficiente se utiliza para medir la desigualdad en la distribución del ingreso en un determinado grupo de población y varía de cero (equidad perfecta) a 1 (desigualdad absoluta).

\section{Referencias bibliográficas}

Banco de México (2006), Indicadores económicos, disponible en http://www.banxico. org.mx.

Cácerez, F. y R. Rubalcava (1994), "El ingreso de los hogares", Instituto Nacional de Estadística Geografía e Informática, Aguascalientes.

Casco, A. y A. Rosenzweig (2000), La política sectorial agropecuaria en México: balance de una década, Instituto Interamericano de Cooperación para la Agricultura (IICA), México.

CEPAL (2005), "México: crecimiento agropecuario, capital humano y gestión del riesgo", LC/Mex/L.686, Santiago.

Cruz, I. (1995), "Transformaciones en el financiamiento rural mexicano durante el sexenio salinista, balance y tendencias 1988-1994", Cuadernos Agrarios, núm. 12, México.

De la Peña, S. (1991), La formación del capitalismo en México, Siglo xxı Editores, México.

FMI (2003), Estadísticas Financieras Internacionales, ediciones de 1998, 2003 y 2005, Washington, DC.

Fritscher, M. y C. Steffen (1994), "Políticas neoliberales y cambio productivo en el agro mexicano: su impacto regional", en M. Bassols (coord.), Campo y ciudad en una era de transición: problemas y desafíos, UAM-Iztapalapa, México, DF.

Gordillo, G., A. de Janvry y E. Sadoulet, La segunda reforma agraria de México: respuestas de familias y comunidades, 1990-1994, El Colegio de México y Fondo de Cultura Económica, México, DF.

Hansen, R. (1993), La política del desarrollo mexicano, Siglo XXI Editores, México, DF.

INEGI Y CEPAL (1994), "La evolución de la pobreza en México, 1984-1992", México, DF.

INEGI (2000), Encuesta Nacional de Empleo 1998, Aguascalientes.

Lustig, N. (1994), Hacia la reconstrucción de una economía, El Colegio de México y Fondo de Cultura Económica, México, DF.

ocde (2005), Agricultural Policies in OECD Countries. Monitoring and Evaluation, París.

OCDE (1997), Examen de las políticas agrícolas de México, París.

Prud'Homme, J. (1995), Impacto social de las políticas de ajuste en el campo mexicano, Editorial Plaza y Valdes, México, DF.

Rosenzweig, A. (2005), "El debate sobre el sector agropecuario mexicano en el Tratado de Libre Comercio de América del Norte", CEPAL, LC/Mex/ L.650/Rev. 1, México, DF., marzo de 2005

Rueda, I. (1998), México: crisis, reestructuración económica, social y política 1982-1996, Siglo XXI Editores, México, DF.

Salcedo, S. (1999), "Impactos diferenciados de las reformas sobre el agro mexicano: productos, regiones y agentes", CEPAL, Santiago.

Salinas, E. (1995), "La modernización de la agricultura mexicana 1988-1994", en A. Sánchez y J. González (coord.), Reestructuración de la economía mexicana. Integración a la economía Mundial y la Cuenca del Pacífico, Universidad Autónoma Metropolitana-RNICP, México, 1995.

Solís, L. (2000), La realidad económica mexicana: retrovisión y perspectivas, Fondo de Cultura Económica, México, DF.

UAM (1995), Perspectivas de la empresa y la economía mexicana frente a la reestructuración productiva, México, DF. 